Short communication

\title{
Benzyl benzoate and dibenzyl ether from of benzoic acid and benzyl alcohol under microwave irradiation using a $\mathrm{SiO}_{2}-\mathrm{SO}_{3} \mathrm{H}$ catalyst
}

\author{
Sandro L. Barbosa ${ }^{\text {a,* }}$, Myrlene Ottone ${ }^{\text {a }}$, Maisa C. Santos ${ }^{\text {, }}$ Gelson C. Junior ${ }^{\text {a }}$, Camila D. Lima ${ }^{\text {a }}$ \\ Giuliano C. Glososki ${ }^{\mathrm{b}}$, Norberto P. Lopes ${ }^{\mathrm{b}}$, Stanlei I. Klein ${ }^{\mathrm{c}}$ \\ a Pharmacy Department, Federal University of the Jequitinhonha and Mucuri Valleys, Rodovia MGT 367, Km 583, CEP $39100-000$ Diamantina, MG, Brazil \\ b Ribeirão Preto Faculty of Pharmaceutical Sciences, São Paulo University, Av. Do Café s/n, CEP 14040-903 Ribeirão Preto, SP, Brazil \\ c Department of General and Inorganic Chemistry, São Paulo State University, R. Prof. Francisco Degni 55, CEP 14800-960 Araraquara, SP, Brazil
}

\section{A R T I C L E I N F O}

\section{Article history:}

Received 16 February 2015

Received in revised form 23 April 2015

Accepted 27 April 2015

Available online 30 April 2015

\section{Keywords:}

Solvent free reactions

Microwave irradiation

Sulfonated silica catalyst

Fischer esterification

Benzyl benzoate

Dibenzyl ether

\begin{abstract}
A B S T R A C T
A sulfonated silica gel of small surface area with large pore diameters was prepared from the sodium silicate obtained from the reaction of construction sand and sodium carbonate, and sulfated with concentrated sulfuric acid. At 7\%-w/w it promotes in 5 min the Fischer-Speier esterification of benzoic acid/benzyl alcohol in 93\% yields, and at higher concentrations, dibenzyl ether is produced selectively and quantitatively, in solvent free reactions induced by microwave irradiation.
\end{abstract}

C 2015 Elsevier B.V. All rights reserved.

\section{Introduction}

The Fischer-Speier esterification is the direct route for the obtention of esters. The mechanism involves the protonation of the carboxyl oxygen of an acid, with the subsequent attack of an alcohol to the positively polarized carboxylic carbon. This step is hampered by sterically demanding alcohols and/or acids. To make things worse, the reaction is reversible, because the product ester is prone to protonation and attack by the water formed. This makes the synthesis of important esters, such as benzyl benzoate, very difficult, even if the water from the reaction is removed from the equilibrium. To overcome these difficulties, different authors have suggested indirect routes, involving benzaldehyde [1,2], benzyl chloride [3,4], and cross-dehydrogenative coupling reactions [5]. A Fisher esterification was accomplished using a sulfonic acid imidazole ionic liquid, in reactions promoted by microwave (MW) irradiation [6,7].

Our group described the application of Lewis acidic silicas and aluminas as catalysts in esterifications promoted by MW irradiation [8], but they were not able to produce esters when both reactants bore aromatic rings. The possibility that Bronsted acidic silicas could work, reinforced after the report of the esterification of fatty acids by silicas treated with $\mathrm{H}_{2} \mathrm{SO}_{4}$ [9], prompted us to develop a protocol using $\mathrm{SiO}_{2}-\mathrm{SO}_{3} \mathrm{H}$ as catalyst

\footnotetext{
* Corresponding author.

E-mail address: sandro.barbosa@ufvjm.edu.br (S.L. Barbosa).
}

under MW irradiation; the new catalyst is water tolerant, and the catalyst/aromatic alcohol ratio can be tuned to produce dibenzyl ether.

\section{Experimental}

SEM micrographs were performed on a Zeiss VEVO 50, EDS with an IXRF Systems 500. FTIR recorded as $\mathrm{KBr}$ pellets in a Varian 640 spectrometer. Reacted contents and yields were determined with a $\mathrm{GC} /$ MS-QP 2010/AOC-5000 AUTO INJECTOR/Shimadzu spectrometer, with a $30 \mathrm{~m}$ Agilent J\&W GC DB-5 MS column, measured at $70 \mathrm{eV}$. XRD patterns collected in a RIGAKU diffractometer at $30 \mathrm{kV}$ and $20 \mathrm{~mA}$ using $\mathrm{CuK}_{\alpha}$ radiation. DTA carried out using a Perkin Elmer 1700 analyzer.

\subsection{Silica gel and sulfonated silica}

$300.0 \mathrm{~g}$ of sand and $600.0 \mathrm{~g}$ of $\mathrm{Na}_{2} \mathrm{CO}_{3}$ were homogenized in porcelain crucibles, and heated at $850{ }^{\circ} \mathrm{C}$ for $4 \mathrm{~h}$. The hot mixtures were transferred to a glass frit and washed with $600-900 \mathrm{~mL}$ of boiling water. The filtered solution was acidified to $\mathrm{pH}=1$ with $\mathrm{HCl}$, the white precipitate filtered, and dried at $400{ }^{\circ} \mathrm{C}$. The resulting silica was passed through a 24 mesh sieve for standardization. $10.0 \mathrm{~g}$ of this silica was mixed with $10.0 \mathrm{~mL}$ of $\mathrm{H}_{2} \mathrm{SO}_{4}$ and stirred at room temperature for $12 \mathrm{~h}$, filtered and dried at $150{ }^{\circ} \mathrm{C}$ for $4 \mathrm{~h}$, cooled and stored in a desiccator. The acid 
strength of $1.44 \mathrm{mmol}$ of $\mathrm{H}^{+} /$gram of catalyst was determined by potentiometric titration.

\subsection{Typical procedures}

In all reactions involving $\mathrm{SiO}_{2}-\mathrm{SO}_{3} \mathrm{H}$ the amount of reagents benzoic acid $(0.6839 \mathrm{~g}-5.6 \mathrm{mmol})$ and benzyl alcohol $(0.1081 \mathrm{~g}-1.0 \mathrm{mmol})$ was used as standard. The amount of catalyst on each run was adjusted to maintain a weigh-to-weigh relation to the alcohol. All reactions were irradiated in an unmodified MW oven $(900 \mathrm{GHz}) / 360 \mathrm{~W}$ [8] using an unstoppered $125 \mathrm{~mL}$ two-necked round bottom flask, and the final temperature of the slurries did not exceed $73^{\circ} \mathrm{C}$.

\subsection{Synthesis of benzyl benzoate}

a) $\mathrm{H}_{2} \mathrm{SO}_{4}$ catalyst: In this reaction, the amount of $\mathrm{H}_{2} \mathrm{SO}_{4}$ was adjusted so that the total $\mathrm{H}^{+}$content (as a monoprotic acid) corresponded to the protons in $\mathrm{SiO}_{2}-\mathrm{SO}_{3} \mathrm{H} 20 \%-\mathrm{w} / \mathrm{w}$ catalyst/alcohol; the required standard quantities were scaled up 100 -fold.

Benzoic acid ( $68.39 \mathrm{~g}-0.56 \mathrm{~mol})$, benzyl alcohol (10.81 g-0.10 mol) and $0.080 \mathrm{~g}$ of concentrated $\mathrm{H}_{2} \mathrm{SO}_{4}\left(7.8 \times 10^{-4} \mathrm{~mol}\right)$ were irradiated for $5 \mathrm{~min}$, with a final temperature of $110{ }^{\circ} \mathrm{C}$. The reaction vessel was cooled to room temperature, and the total mixture analyzed by $\mathrm{CG} / \mathrm{MS}$, which evidenced total conversion of the alcohol to benzyl benzoate.

b) $\mathrm{SiO}_{2}-\mathrm{SO}_{3} \mathrm{H}$ catalyst: in the reaction flask it was added $0.0076 \mathrm{~g}$ of the $\mathrm{SiO}_{2}-\mathrm{SO}_{3} \mathrm{H}(7 \%-\mathrm{w} / \mathrm{w})$ and the standard quantities of both reagents. After $5 \mathrm{~min}$ of irradiation the temperature of the reaction rose to $70{ }^{\circ} \mathrm{C}$. The vessel was cooled to room temperature, $30 \mathrm{ml}$ of diethyl ether was added, and the mixture filtered. The organic extract was washed with $10.0 \mathrm{~mL}$ of saturated $\mathrm{NaHCO}_{3}$, dried over anhydrous $\mathrm{MgSO}_{4}$ and concentrated under reduced pressure. The residue was purified by chromatographic column using hexane and ethyl acetate as eluent to obtain the pure benzyl benzoate as colorless oil. Yield. $0.2080 \mathrm{~g}$ and $98.97 \%$. The filtered catalyst was washed with $10 \mathrm{~mL}$ diethyl ether, and dried at $150{ }^{\circ} \mathrm{C}$ for $2 \mathrm{~h}$ before reuse.

\subsection{Synthesis of dibenzyl ether}

a) In excess benzoic acid: $\mathrm{SiO}_{2}-\mathrm{SO}_{3} \mathrm{H}(0.0216 \mathrm{~g}-20 \%-\mathrm{w} / \mathrm{w})$ and the standard quantities of both reagents were irradiated for $5 \mathrm{~min}$, final temperature $69^{\circ} \mathrm{C}$. CG/MS analysis of the cold mixture showed total conversion of the alcohol.

b) In the absence of benzoic acid: $\mathrm{SiO}_{2}-\mathrm{SO}_{3} \mathrm{H}(0.0216 \mathrm{~g}-20 \%-\mathrm{w} / \mathrm{w})$ and the standard amount of benzyl alcohol were irradiated for $5 \mathrm{~min}$, final temperature $70^{\circ} \mathrm{C}$. The crude mixture showed total conversion of the alcohol (by CG/MS).

\section{Results and discussion}

\subsection{Silica gel and catalyst characterization}

The non-crystalline nature of the silica gel and of the sulfonated catalyst was confirmed by XRD, which presented broad peaks centered at $2 \theta=23^{\circ}$.

The infrared spectrum of the silica (Fig. 1) is also representative of an amorphous gel. The characteristic bands around 3400 and $1630 \mathrm{~cm}^{-1}$ are associated with the stretching and bending modes of molecular water, with the shoulder at 3200 and the weak absorption at $960 \mathrm{~cm}^{-1}$ related to the $-\mathrm{OH}$ and $\mathrm{Si}-\mathrm{OH}$ vibrations of the silanols. Also characteristics are the bands at 1090 and the associated shoulder at $1190 \mathrm{~cm}^{-1}$, relative to the asymmetric stretchings of the $\mathrm{Si}-\mathrm{O}-\mathrm{Si}$ bonds. The absorption at $800 \mathrm{~cm}^{-1}$ of the ring structured $\mathrm{SiO}_{4}$ tetrahedra ( $\mathrm{Si}-\mathrm{O}-\mathrm{Si}$ symmetric stretchings), the $\mathrm{Si}-\mathrm{O}-\mathrm{Si}$ bending vibrations at $470 \mathrm{~cm}^{-1}$, and the observable overtones typical of the amorphous silicas in the region of $1800-1900 \mathrm{~cm}^{-1}$ complete the spectrum of the gel. The IR spectrum of the sulfonated silica showed remarkable differences. For instance, the $\mathrm{H}_{2} \mathrm{O}$ bands at $3400 \mathrm{~cm}^{-1}$ become much broader, with additional intramolecular hydrogen bond features from 2900 to $2100 \mathrm{~cm}^{-1}$, with the concomitant increase of the $\mathrm{H}_{2} \mathrm{O}$ bending at $1637 \mathrm{~cm}^{-1}$. These changes reflect the accommodation of additional water molecules via hydrogen bonds to the $-\mathrm{SiOH}$ and $-\mathrm{O}-\mathrm{SO}_{3} \mathrm{H}$ groups. The splitting of the absorptions from 1210 to $1040 \mathrm{~cm}^{-1}$ in that spectrum is noteworthy, which indicates a profound modification of the overall surface structure of the $\mathrm{Si}-\mathrm{O}-\mathrm{Si}$ original arrangement, also reflected in the further weakening of the $\mathrm{Si}-\mathrm{OH}$ band at $960 \mathrm{~cm}^{-1}$. The contribution of the groups $-\mathrm{O}-\mathrm{SO}_{3} \mathrm{H}$ to the absorptions of the IR spectrum of the catalyst is ambiguous, because of the close proximity of the atomic weights of silicon and sulfur oxygen tetrahedra. However, one might assume that the enhancement of the $\mathrm{Si}-\mathrm{O}-\mathrm{Si}$ longitudinaltransverse optical vibration (LO) absorption at $1210 \mathrm{~cm}^{-1}$ and the transversal optical (TO) rocking of the Si-O-Si bonds at $592 \mathrm{~cm}^{-1}$,

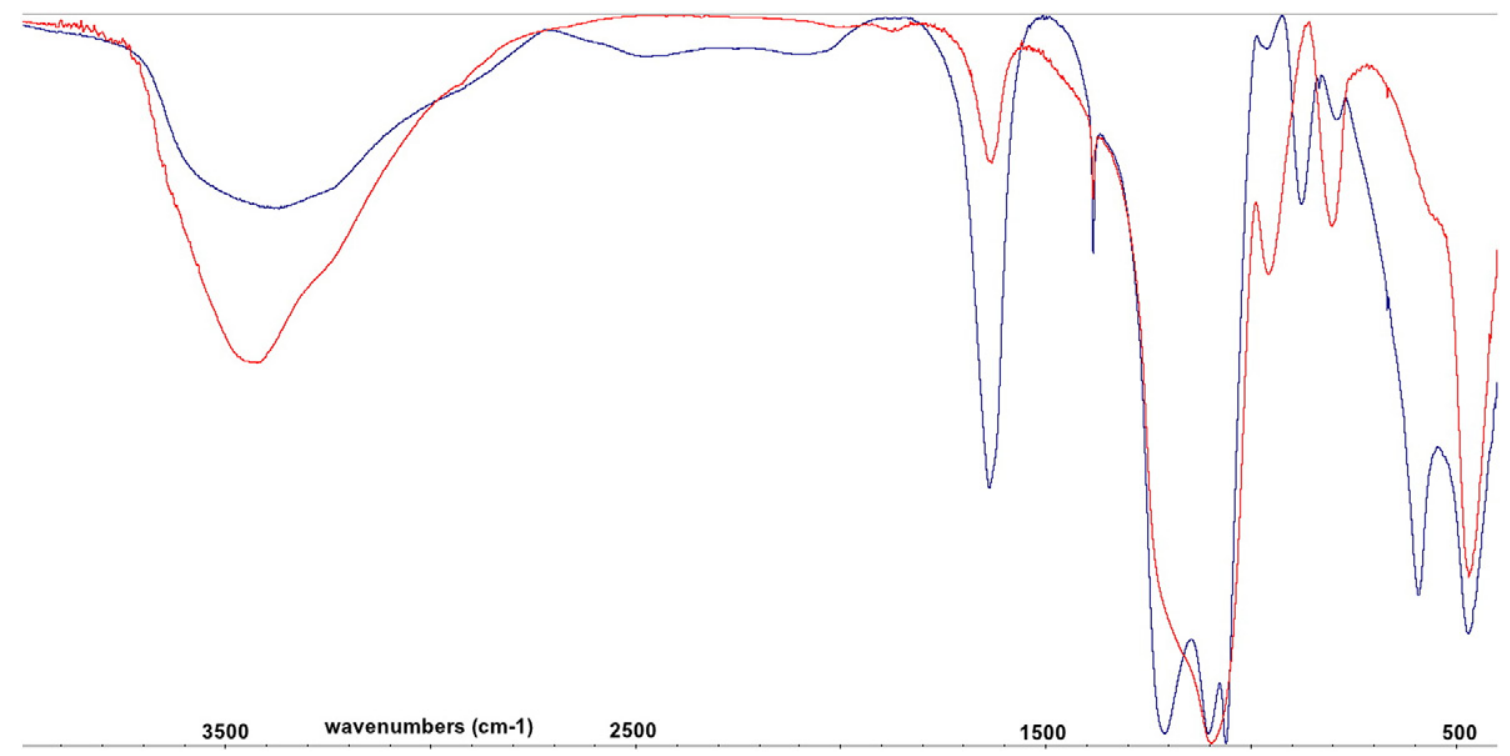

Fig. 1. IR spectrum of silica (red) and catalyst (blue). 


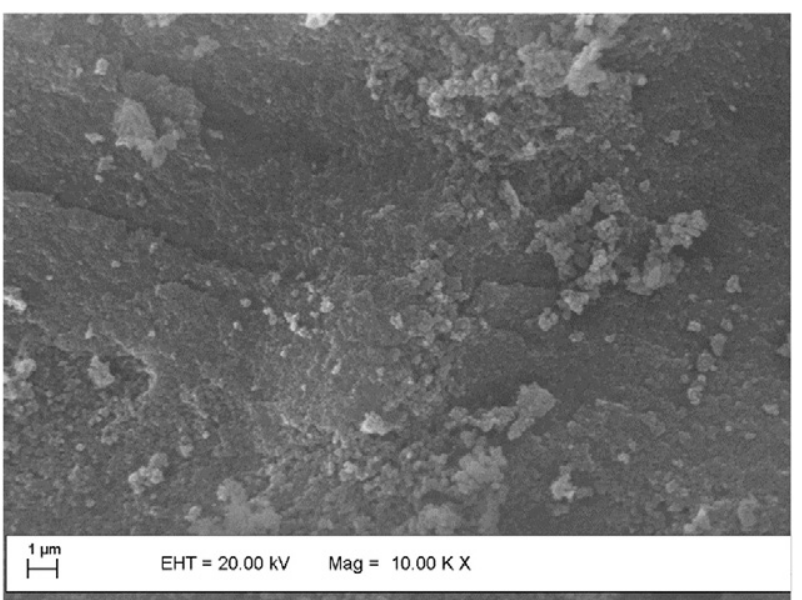

Fig. 2. FE-SEM images of the amorphous silica gel.

may be due to the presence of those $-\mathrm{OSO}_{3} \mathrm{H}$ groups of the catalyst [ 10 , 11].

The differences between the original silica and the sulfonated material are also evident from the FE-SEM images shown in Figs. 2-3. The even distributions of the particles of the silica, responsible for its large surface area, form aggregates upon sulfonation, which are well separated by macropores several nanometers large.

BET analysis reinforced the changes that occurred upon sulfonation. The lowering of the specific surface area was found from 37.86 to $23.10 \mathrm{~m}^{2} \mathrm{~g}^{-1}$, and the widening of the pore diameters to $3.73 \mathrm{~nm}$. The $\mathrm{N}_{2}$ adsorption-desorption isotherms of the gel and catalyst (Fig. 4), were typical for mesoporous materials.

TG/DTG/DTA showed the decomposition of the silica gel in synthetic air taking place in one stage, related to the endothermic elimination of water molecules. The decomposition of the catalyst takes place in two stages, from room temperature to $169.39^{\circ} \mathrm{C}$, related to the elimination of water molecules, and up to $240^{\circ} \mathrm{C}$, corresponding to the endothermic loss of $-\mathrm{SO}_{3} \mathrm{H}$ groups.

\subsection{Reactions}

To evaluate the action of our synthetic silicas for the specific reaction of condensing benzoic acid and benzyl alcohol, we run a blank experiment using the silica gel as the catalyst. Reagents and gel were irradiated for $5 \mathrm{~min}$, and no products were detected. However, when reagents were irradiated for $5 \mathrm{~min}$ in the presence of only $1.0 \%-\mathrm{w} / \mathrm{w}$ sulfonated

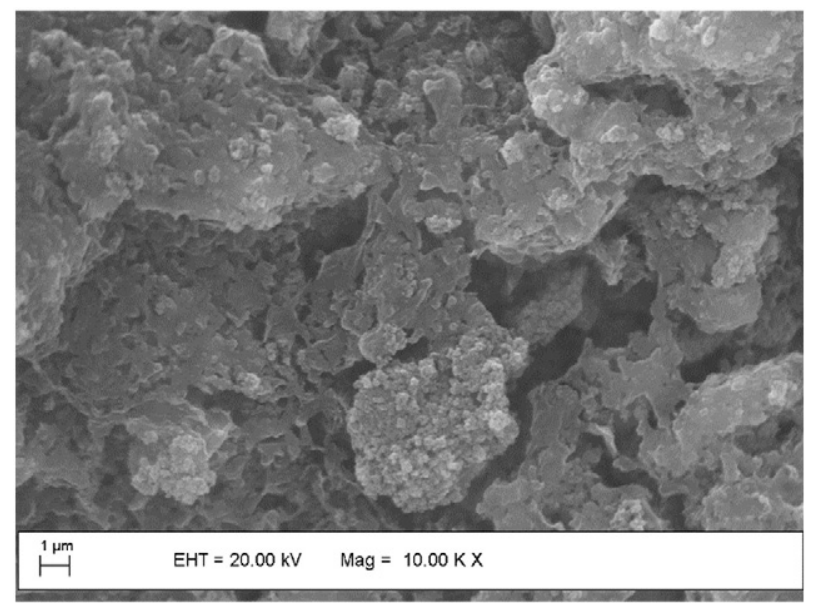

Fig. 3. FE-SEM images of the sulfonated silica.

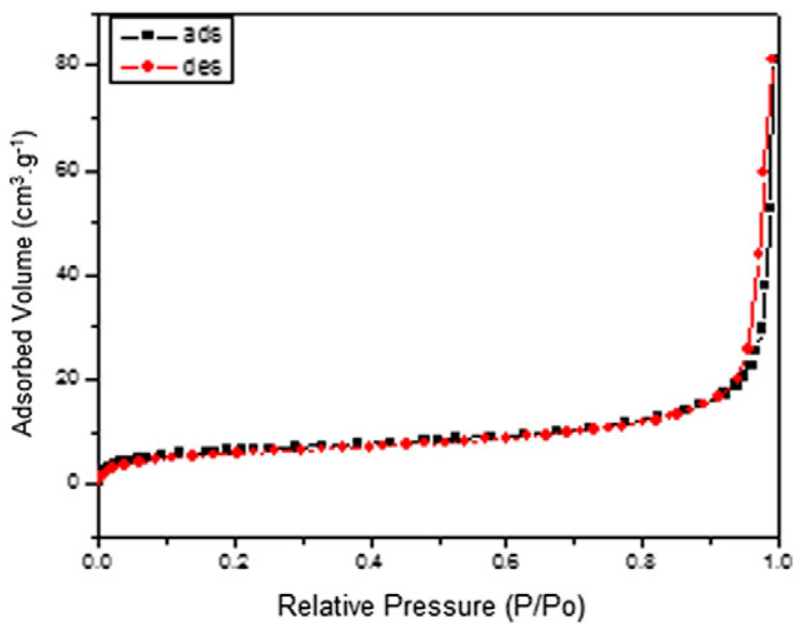

Fig. 4. $\mathrm{N}_{2}$ adsorption-desorption isotherms of the catalyst.

catalyst/alcohol, $18.97 \%$ of benzyl benzoate was formed (by CG/MS). Different ratios of sulfonated silica were tested, and, surprisingly, at $7.0 \%$ catalyst/alcohol, the maximum yield of benzyl benzoate was achieved (98.97\%, entry 8 in Table 1 ), but at this concentration, a novel spot in the TLC monitoring plates, and its corresponding new peak in CG/MS, indicated the formation of dibenzyl ether (1.03\%). Further experiments indicated that higher yields of ether could be obtained with increased amounts of catalyst; at $20 \%-w / w$, only the ether was formed. The maximum yield of benzoate free from ether is $93.61 \%$, with a catalyst load of $6 \%$; this yield is superior to that obtained by us using $\mathrm{NbCl}_{5}$ catalyst [12] or by others using ionic liquids [6,7]. Similar yields can be obtained in about $4 \mathrm{~h}$ using conventional heating at $80^{\circ} \mathrm{C}$.

\subsection{Mechanism and the reusability of $\mathrm{SiO}_{2}-\mathrm{SO}_{3} \mathrm{H}$}

In the Fischer-Speier mechanism, it is the acid partner who is activated by protonation from a Bronsted acid. Accordingly, in our laboratories, when an excess of benzoic acid, benzyl alcohol and concentrated $\mathrm{H}_{2} \mathrm{SO}_{4}$ were irradiated in a microwave oven, the only product obtained is benzyl benzoate. However, the same alcohol to acid ratio of reactants shows the interesting shift, moving from 100\% benzyl benzoate to $\sim 100 \%$ dibenzyl ether with the increase of the $\mathrm{w} / \mathrm{w}$ ratio of the catalyst (Table 1). We had noted this shift in concurring esterification/ etherification reactions, the etherification taking over as the $\mathrm{w} / \mathrm{w}$ ratio of the catalyst to alcohol increased [10], and recently, Chang et al. noted this effect in the acetal formation versus esterification of acetaldehyde and butanol-1 promoted by their $\mathrm{SiO}_{2}-\mathrm{SO}_{3} \mathrm{H}$ catalyst (from chlorosulfonic acid and silica) [13]. These evidences indicate a relation of the catalysts Lewis basic sites to an "activated" alcohol, and the following reaction scheme can be proposed (Fig. 5; ${ }^{* *}$ refers to catalyst bound species; $\mathrm{Ph}=$ phenyl, and $\mathrm{Bz}=$ benzyl):

Table 1

Esterification/etherification reactions.

\begin{tabular}{llcl}
\hline Catalyst $(\mathrm{w} / \mathrm{w} \%)$ & Temp. $\left({ }^{\circ} \mathrm{C}\right)$ & \% yield Benzyl ether & \% yield Benzyl Benzoate \\
\hline 1.0 & 73 & & 18.97 \\
2.0 & 72 & & 40.29 \\
4.0 & 72 & & 85.47 \\
6.0 & 72 & & 93.61 \\
7.0 & 70 & 1.03 & 98.97 \\
8.0 & 71 & 5.89 & 94.11 \\
9.0 & 70 & 6.39 & 93.61 \\
10.0 & 71 & 14.64 & 85.36 \\
20.0 & 69 & 100.00 & \\
\hline
\end{tabular}

Reaction conditions: benzoic acid, $5.60 \mathrm{mmol}$; benzyl alcohol, $1.00 \mathrm{mmol}$; MW 360 W, 5 min. 
Low catalyst load $(1 \sim 6 \%)$

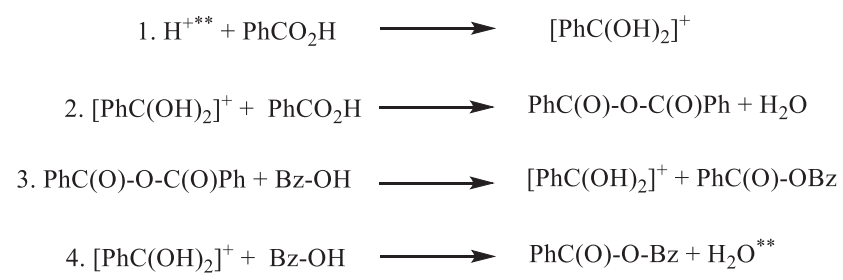

High catalyst load (6 20\%)

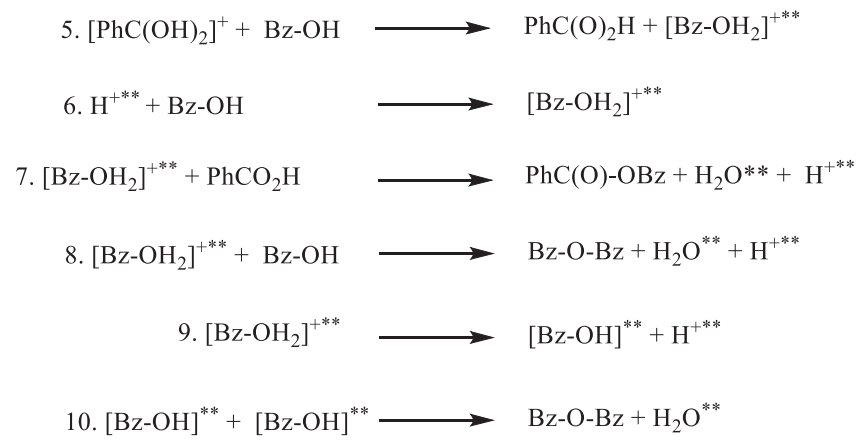

Fig. 5. Suggested reaction scheme for the esterification and etherification of aromatic substrates by $\mathrm{SiO}_{2}-\mathrm{SO}_{3} \mathrm{H}$.

Reaction 1 represents the classical protonation of the acid by the $\mathrm{SiO}_{2}-\mathrm{SO}_{3} \mathrm{H}$ Bronsted sites. The protonated species can react with the excess acid forming an anhydride, but this would be too reactive towards hydrolysis (reaction 2) or decomposition by the alcohol (reaction 3); the net effect of ( 2 and 3 ) would appear as an increase of the ester content in the mixture. Reactions 4-10 should be highly dependent on the reagents/catalyst w/w ratio; at low catalyst ratios, reaction 4 would be responsible for the retention of water, favoring the production of the ester. At high catalyst ratios, ours [10] and others' [13] results point to the increase of the role of the adsorbed alcohol. Proton exchange between solvated species or direct protonation from the catalyst and subsequent adsorption of the cationic alcohol intermediate (reactions 5 and 6) could bring about the formation of ester (reaction 7) and ether (reaction 8) or, more likely, provide a mechanism through which the adsorbed species could interact at the level of the surface of the catalyst (reactions 9 and 10), therefore producing high quantities of ether, despite the enormous quantity of organic acid used in the reactions (mol ratio acid/alcohol 5.6:1); in this particular, the textural properties of this $\mathrm{SiO}_{2}-\mathrm{SO}_{3} \mathrm{H}$ catalyst, such as small surface area with large pore diameters, should facilitate water adsorption and benzyl alcohol activation.
Table 2

Catalyst reusability.

\begin{tabular}{lll}
\hline Run & Catalyst acidity $\left(\mathrm{mmol} \mathrm{H}^{+} / \mathrm{g}\right)$ & \%Yield \\
\hline 1 & 1.44 & 98.97 \\
2 & 0.35 & 97.63 \\
3 & 0.22 & 96.61 \\
4 & 0.20 & 95.11 \\
5 & 0.11 & 82.07 \\
\hline
\end{tabular}

Catalyst load 7\%; MW 360 W, 5 min. Products quantified by CG/MS.

The amenable conditions of the reported preparations of benzyl benzoate and dibenzyl ether facilitate the catalyst recovery, which is filtered from the reaction mixture, washed with ether and dried at $150{ }^{\circ} \mathrm{C}$. In assessing the reusability, a sample of the spent catalyst was titrated before each run, (Table 2). Note that the quantity of sulfonic groups on the catalyst enough for sustaining $0.20 \mathrm{mmol} \mathrm{H}^{+} / \mathrm{g}$ (run 4, Table 2), still promotes a very good esterification yield, probably influenced by the high water tolerance of the catalyst, which is characteristic of its textural parameters.

\section{Conclusion}

A low cost silica gel produces a highly efficient sulfonated catalyst for microwave-induced preparation of benzyl benzoate in $93 \%$, by the esterification of the otherwise unreactive benzoic acid and benzyl alcohol. The small surface area and large pores of the catalyst also facilitate quantitative and selective preparation of dibenzyl ether.

\section{Acknowledgments}

This work was supported by the CNPq, Fapesp and Fapemig.

\section{References}

[1] O. Kamm, W.F. Kamm, Org. Synth. Coll. 1 (1941) 104-105 (1922, Vol. 2, 5-6).

[2] N.S. Nudelman, S. Mendiara, Tetrahedron Lett. 13 (1997) 2245-2248.

[3] S. Asai, H.N.M. Tanabe, K. Sakamoto, Ind. Eng. Chem. Res. 33 (1994) 1687-1691.

[4] O. Chantarasriwong, D.O. Jang, W. Chavasiri, Synth. Commun. 38 (2008) 2845-2856.

[5] J. Zhou, C. Jin, X. Li, W. Su, RSC Adv. 5 (2015) 7232-7236.

[6] X. Li, W. Eli, Catal. Commun. 9 (2008) 2264-2268.

[7] R. Kore, R. Srivastava, Catal. Commun. 12 (2011) 1420-1424.

[8] S.L. Barbosa, M.J. Dabdoub, G.R. Hurtado, S.I. Klein, A.C.M. Baroni, C. Cunha, Appl. Catal. A Gen. 313 (2006) 146-150.

[9] M.K. Yadav, A.V. Kothari, D.G. Naik, V.K. Gupta, Green Chem. Lett. Rev. 2 (2009) $181-187$.

[10] A.-M. Putz, M.V. Putz, Int. J. Mol. Sci. 13 (2012) 15925-15941.

[11] R.M. Almeida, T.A. Guiton, C.G.J. Pantano, Non-Cryst. Solids 119 (1990) 238-241.

[12] S.L. Barbosa, G.R. Hurtado, S.I. Klein, V.L. Junior, M.J. Daboub, C.F. Guimaraes, Appl. Catal. A Gen. 345 (2008) 9-13.

[13] J. Ye, C. Liu, Y. Fu, S. Peng, J. Chang, Energy Fuel 28 (2014) 4267-4272. 